\title{
Deducing Optimal Classification Algorithm for Heterogeneous
} Fabric

\author{
Omar Alfarisi ${ }^{1}$, Zeyar Aung $^{1}$, and Mohamed Sassi ${ }^{1}$
}

${ }^{1}$ Affiliation not available

February 15, 2022

\begin{abstract}
For defining the optimal machine learning algorithm, the decision was not easy for which we shall choose. To help future researchers, we describe in this paper the optimal among the best of the algorithms. We built a synthetic data set and performed the supervised machine learning runs for five different algorithms. For heterogeneous rock fabric, we identified Random Forest, among others, to be the appropriate algorithm.
\end{abstract}

\section{Hosted file}

deducing-optimal-ml-algorithms-for-heterogeneity_o_alfarisi_20220104v4.pdf available at https://authorea.com/users/458850/articles/556205-deducing-optimal-classificationalgorithm-for-heterogeneous-fabric 